\title{
LAND COVER CHANGE ANALYSIS IN THE STATE OF CALIFORNIA USING NLCD DATA
}

\author{
Indumathi Jeyachandran ${ }^{1, *}$ \\ 1, ${ }^{*}$ Department of Civil and Environmental Engineering, San Jose State University, San Jose, CA-95192, USA, ORCiD: 0000-0002- \\ 2599-385X - indumathi.jeyachandran@sjsu.edu
}

KEY WORDS: Land cover, NLCD, Urbanization, Change Analysis, impervious surfaces.

\begin{abstract}
:
Land cover change is critical to be monitored as land cover change has significant impacts on flooding, ground water recharge, and urban air temperature. In this paper, key findings from a land cover change analysis study performed in the State of California are presented. National Land Cover Database (NLCD) data from the Multi-Resolution Land Characteristics Consortium (MRLC) was used for this study. Time series of NLCD data during the time period of 2001 through 2016 was used for the analysis. NLCD data processing was done in ArcMap 10.6.1. This paper includes the methodology in detail, and the results of the analysis. Results of the study indicate a significant increase in impervious surfaces, and a significant decrease in forest land cover.
\end{abstract}

\section{INTRODUCTION}

Urbanization has been accompanied by abundant increase of built surfaces, and decrease in vegetated surfaces (Kondoh and Nishiyama, 2000). Abundance of built surfaces has led to an increase in runoff (Ando et al., 1984; DeWalle et al., 2000).

Land Cover change analysis serves as a great means to understand impacts of urbanization, and provides an estimate of the percent increase or decrease in the areal extent of built surfaces and vegetated areas. The impacts of land cover changes include the following: reduced evapotranspiration due to decrease in vegetation (Peterson et al., 1995; Dow and DeWalle, 2000), increased urban air temperatures due to increase in built surfaces and decrease in vegetation (Landsberg, 1981; Akbari et al., 2001), formation of the urban heat island (UHI) (Oke, 1987; Grimmond and Oke, 1995). Increase in urban air temperature leads to an increase in energy usage for air-conditioning in warm summer months (Akbari et al., 2001).

Remote Sensing data is being increasingly used for land cover change monitoring due to the availability of time series of data. Landsat data and other regionally available remote sensing data has been used for LULC change analysis (Singh and Dubey, 2012; Bijender and Joginder, 2014; Nguyen et al., 2016; Utomo and Kurniawan, 2016; Wan et al., 2019).

In this paper, timer series of National Land Cover Database (NLCD) land cover data was used for the land cover change analysis in the State of California during the time period of 2001 through 2016. The organization of the paper is as follows: Section 2 focuses on the study area and data used, Section 3 focuses on the methodology, Section 4 focuses on the results and discussion, and Section 5 is the conclusion section of the paper.

\section{STUDY AREA AND DATA}

\subsection{Study Area}

State of California was used as the study area for the land cover change analysis. The area of State of California is 423,970 sq.km. There are 58 counties in the State of California. The case study area is shown in Figure 1.

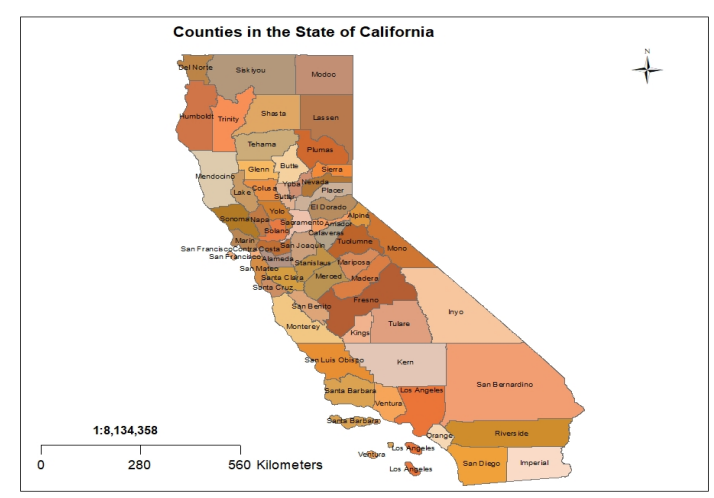

Figure 1. Study Area

\subsection{Data Used}

National Land Cover Database (NLCD) land cover data downloaded from the Multi- Resolution Land Characteristics Consortium Website was used for the land cover change analysis.

\subsection{Time Period of Analysis}

Land cover change analysis was performed for the time period of 2001 through 2016. 


\section{METHODOLOGY}

NLCD data for Contiguous United States (CONUS) was downloaded from the Multi- Resolution Land Characteristics Consortium Website for the following years: 2001, 2004, 2006, 2008, 2011, 2013, 2016. This was the first step in the land cover change analysis.

NLCD data was processed in Esri ArcMap 10.6.1 for the land cover change analysis. A vital step in the land cover change analysis, was clipping the NLCD data to the extent of State of California. For the clipping process, Clip tool in ArcMap was used. State of California's boundary data was used as the clipping extent. To automate and batch process the time series of NLCD data (2001 through 2016), a model was created in Model Builder tool in ArcMap. The created model is shown in Figure 2.

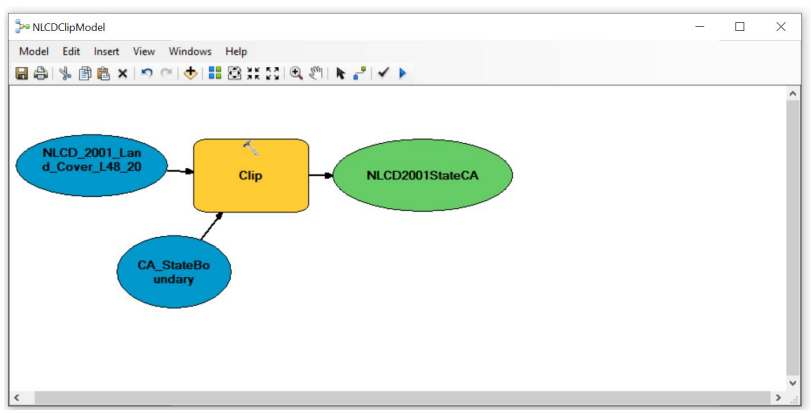

Figure 2. Land Cover Data Clip Model

Once the NLCD data for the years 2001, 2004, 2006, 2008, 2011, 2013, and 2016 were clipped to the study area extent, the area of each land cover type was computed. As the first step, an attribute field for area was added in the attribute table of the clipped NLCD time series data. This step is shown in Figure 3.

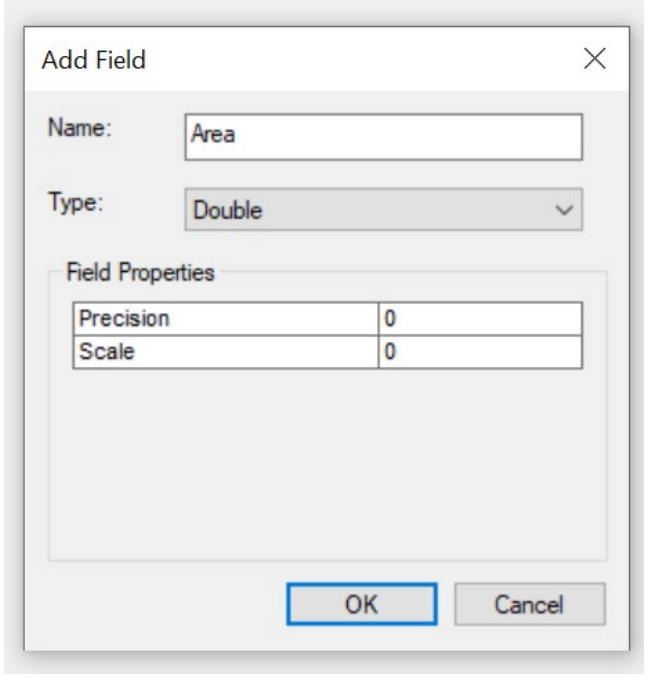

Figure 3. Adding the area field to the Attribute Table

Once the attribute field for area was added, the field calculator tool in ArcMap 10.6.1 was used for the area computation. The field calculator tool for computation of area is shown in Figure 4. Area was computed by multiplying the number of pixels in each cover category by the area of each pixel $(30 \mathrm{~m} \times 30 \mathrm{~m})$ as the resolution of the NLCD data is $30-\mathrm{m}$. The area of each land cover category was computed using Equation 1.

Area $=$ Count $* 30 * 30$

where Area $=$ Area of each land cover type (in square meters) Count $=$ Number of Pixels in each land cover type

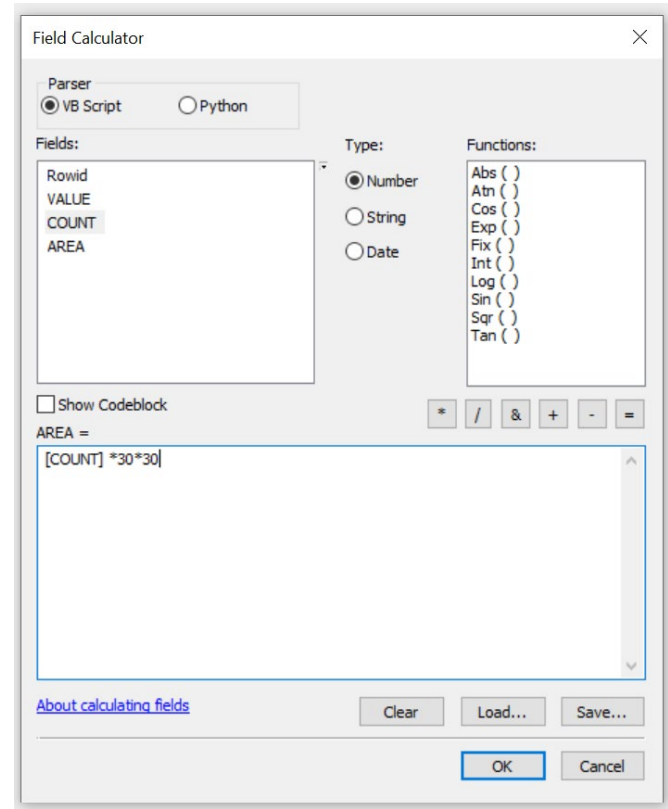

Figure 4. Area calculation using the Field Calculator

The area computed for each land cover category for NLCD 2011 data is shown in Figure 5.

\begin{tabular}{|c|c|c|c|c|}
\hline \multicolumn{5}{|c|}{ Table } \\
\hline & 䁌。 & 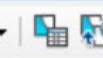 & $\square+$ & \\
\hline \multicolumn{5}{|c|}{ nlcd2011steca } \\
\hline & Rowid & VALUE & COUNT & AREA \\
\hline & 0 & 0 & 101718 & 91546200 \\
\hline & 1 & 11 & 21797028 & 19617325200 \\
\hline & 2 & 12 & 31711 & 28539900 \\
\hline & 3 & 21 & 12593462 & 11334115800 \\
\hline & 4 & 22 & 6865256 & 6178730400 \\
\hline & 5 & 23 & 7798324 & 7018491600 \\
\hline & 6 & 24 & 2107116 & 1896404400 \\
\hline & 7 & 31 & 21972389 & 19775150100 \\
\hline & 8 & 41 & 2507628 & 2256865200 \\
\hline & 9 & 42 & 90938334 & 81844500600 \\
\hline & 10 & 43 & 9597224 & 8637501600 \\
\hline & 11 & 52 & 179933429 & 161940086100 \\
\hline & 12 & 71 & 64171033 & 57753929700 \\
\hline & 13 & 81 & 2999854 & 2699868600 \\
\hline & 14 & 82 & 42851500 & 38566350000 \\
\hline & 15 & 90 & 1345920 & 1211328000 \\
\hline & 16 & 95 & 3463553 & 3117197700 \\
\hline
\end{tabular}

Figure 5. Attribute Table of NLCD 2011 data

Following the methodology for area computation, the area of each land cover category was computed for the time series of NLCD data for the following years: 2001, 2004, 2006, 2008, 
2011, 2013, and 2016. Further percent change analysis in the land cover categories was performed in Microsoft Excel.

\section{RESULTS AND DISCUSSION}

Results of the land cover change analysis during the time period of 2001 through 2016, show a significant increase in impervious surfaces through the increase in the following land cover categories: low-intensity developed, medium intensity developed, and high-intensity land cover categories. The overall increase in impervious surface from 2001 through 2016 is $33 \%$. The change in impervious surfaces from 2001 through 2016 is shown in Figure 6.

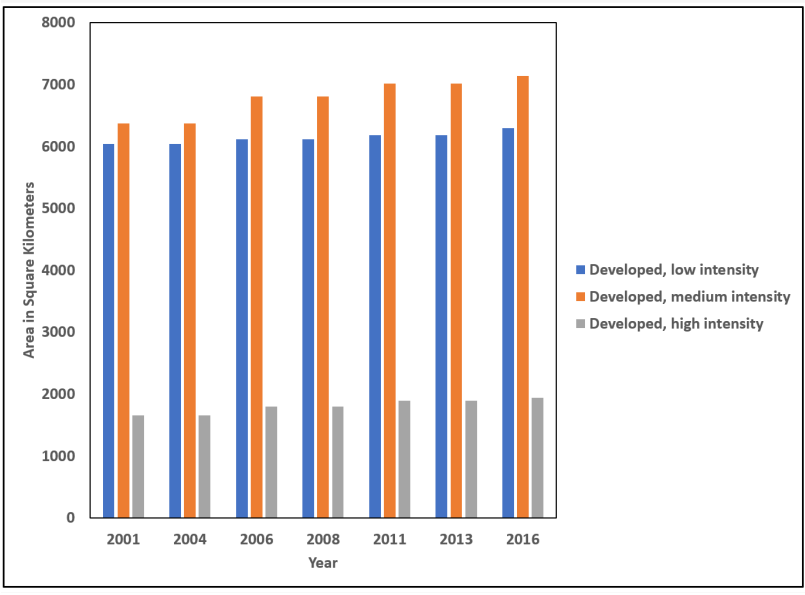

Figure 6. Impervious Surfaces Area from 2001 through 2016

The percent change in each land cover category from 2001 through 2016 is shown in Table 1. Negative values indicate a percent decrease in the area of the land cover, whereas positive values indicate percent increase in the area of the land cover.

\begin{tabular}{|l|c|}
\hline Land Cover Category & $\begin{array}{c}\text { Percent } \\
\text { Increase/Decrease }\end{array}$ \\
\hline Developed, open space & 1.23 \\
\hline Developed, low intensity & 4.20 \\
\hline Developed, medium intensity & 11.98 \\
\hline Developed, high intensity & 17.52 \\
\hline Barren land & 0.95 \\
\hline Deciduous forest & -3.77 \\
\hline Evergreen forest & -7.43 \\
\hline Mixed forest & -12.14 \\
\hline Shrub/scrub & 1.27 \\
\hline Grassland/Herbaceous & 6.99 \\
\hline Pasture/Hay & -9.22 \\
\hline Cultivated Crops & 2.31 \\
\hline Woody Wetlands & 0.18 \\
\hline Emergent Herbaceous Wetlands & 1.00 \\
\hline
\end{tabular}

Table 1. Land Cover Change from 2001 through 2016

Percent change in land cover from 2001 through 2008 is shown in Table 2.

\begin{tabular}{|l|c|c|c|}
\hline & \multicolumn{3}{|l|}{ Percent Increase/Decrease } \\
\hline Land Cover Category & $2001-2004$ & $2004-2006$ & $2006-2008$ \\
\hline Developed, open space & 0 & 0.43 & 0 \\
\hline Developed, low intensity & 0 & 1.26 & 0 \\
\hline Developed, medium intensity & 0 & 6.79 & 0 \\
\hline Developed, high intensity & 0 & 9.00 & 0 \\
\hline Barren land & 0.67 & -1.06 & 0 \\
\hline Deciduous forest & -1.15 & -0.23 & 0 \\
\hline Evergreen forest & -1.34 & -0.38 & 0 \\
\hline Mixed forest & -2.81 & -0.98 & 0 \\
\hline Shrub/scrub & -1.05 & -0.22 & 0 \\
\hline Grassland/Herbaceous & 5.92 & -0.19 & 0 \\
\hline Pasture/Hay & -2.30 & -2.88 & 0 \\
\hline Cultivated Crops & 0.36 & 0.04 & 0 \\
\hline Woody Wetlands & 0.54 & -1.80 & 0 \\
\hline Emergent Herbaceous Wetlands & 0.29 & -3.41 & 0 \\
\hline
\end{tabular}

Table 2. Land Cover Change from 2001 through 2008

Percent change in land cover from 2008 through 2016 is shown in Table 3.

\begin{tabular}{|l|c|c|c|}
\hline & \multicolumn{3}{|c|}{ Percent Increase/Decrease } \\
\hline Land Cover Category & $2008-2011$ & $2011-2013$ & $2013-2016$ \\
\hline Developed, open space & -0.14 & 0.00 & 0.94 \\
\hline Developed, low intensity & 0.98 & 0.00 & 1.90 \\
\hline Developed, medium intensity & 3.10 & 0.00 & 1.71 \\
\hline Developed, high intensity & 5.28 & 0.00 & 2.41 \\
\hline Barren land & 0.31 & 1.63 & -0.58 \\
\hline Deciduous forest & -1.30 & -0.05 & -1.10 \\
\hline Evergreen forest & -2.19 & -1.27 & -2.47 \\
\hline Mixed forest & -5.95 & -0.01 & -2.90 \\
\hline Shrub/scrub & 0.37 & 0.85 & 1.33 \\
\hline Grassland/Herbaceous & 2.35 & -0.24 & -0.89 \\
\hline Pasture/Hay & -3.20 & 0.82 & -1.98 \\
\hline Cultivated Crops & 0.67 & 0.18 & 1.05 \\
\hline Woody Wetlands & 0.30 & 1.83 & -0.65 \\
\hline Emergent Herbaceous Wetlands & 1.46 & 3.58 & -0.78 \\
\hline
\end{tabular}

Table 3. Land Cover Change from 2008 through 2016

\section{CONCLUSION}

The results of the land cover change analysis indicate an increase of $33 \%$ in impervious surfaces, a decrease of $24 \%$ in forest land cover, and a decrease of $9 \%$ in pasture land cover. Land Cover Changes are vital to be analyzed to devise urban development plans conducive to creating a sustainable environment. Future research will focus on modeling land cover changes impact on water demand and urban air temperature. 


\section{REFERENCES}

Akbari, H., Pomerantz, M., and Taha, H., 2001. Cool surfaces and shade trees to reduce energy use and improve air quality in urban areas. Solar Energy, 70(3), 295-310.

Ando, Y., Musiake, K., and Takahasi, Y., 1984. Modeling of hydrologic processes in a small urbanized hillslope basin with comments on the effects of urbanization. Journal of Hydrology, 68(1-4), 61-83.

DeWalle, D.R., Swistock, B.R., Johnson, T.E., and McGuire, K.J., 2000. Potential effects of climate change and urbanization on mean annual streamflow in the United States. Water Resources Research, 36(9), 2655-2664.

Dow, C.L., and DeWalle, D.R., 2000. Trends in evaporation and Bowen ratio on urbanizing watersheds in eastern United States. Water Resources Research, 36(7), 1835-1843.

Grimmond, C.S.B., and Oke, T.R., 1995. Comparison of heat fluxes from summertime observations in the suburbs of four North American cities. Journal of Applied Meteorology, 34(4), 873-889.

Kondoh, A., and Nishiyama, J., 2000. Changes in hydrological cycle due to urbanization in the suburb of Tokyo Metropolitan area, Japan. Advances in Space Research, 26(7), 1173-1176.

Landsberg, H., 1981. The Urban Climate. Academic Press, New York.

Nguyen, D.T., Iskandar, I. and Ho, S., 2016. Land cover change and the $\mathrm{CO} 2$ stock in the Palembang City, Indonesia: A study using remote sensing, GIS technique and LUMENs. The Egyptian Journal of Remote Sensing and Space Science, 19(2), 313-321.

Oke, T.R., 1987. Boundary layer climates. Routledge, London.

Peterson, T.C., Golubev, V.S., and Groisman, P.Y., 1995. Evaporation losing its strength. Nature, 377(6551), 687-688.

Singh, V., and Dubey, A., 2012. Land Use Mapping Using Remote Sensing \& GIS Techniques in Naina-Gorma Basin, Part of Rewa District, MP, India. International Journal of Emerging Technology and Advanced Engineering, 2(11), 151156.

Bijender, S., and Bijender, J., 2014. Land use/land cover change of Delhi: a study using remote sensing and GIS techniques. International Research Journal of Earth Sciences, 2(1), pp.15-20.

Utomo, D.H., and Kurniawan, B.R., 2016. Spatio Temporal Analysis Trend of Land Use and Land Cover Change Against Temperature Based on Remote Sensing Data in Malang City. Procedia-Social and Behavioral Sciences, 227, 232-238.

Wan, Heng, Shao, Yang, Campbell, James B, \& Deng, Xinwei. (2019). Mapping Annual Urban Change Using Time Series Landsat and NLCD. Photogrammetric Engineering and Remote Sensing, 85(10), 715-724. DOI: 10.14358/PERS.85.10.715 